\title{
Influence of Nanoparticles on the Structure and Mechanical Properties of Aluminium Alloys
}

\author{
Pavel O. Sukhodaev*a, Victor E. Redkin ${ }^{\text {a }}$, \\ Tatyana A. Bogdanova ${ }^{\mathrm{b}}$ and Victor A. Kuznetsov ${ }^{\mathrm{c}}$ \\ ${ }^{a}$ Siberian Federal University \\ 28 Kyrenskogo Str., Krasnoyarsk, 660074, Russia \\ ${ }^{b} L t d$. "K\&K" \\ 42 Pogranichnikov Str., Krasnoyarsk, 660111, Russia \\ 'Ltd. "Nanomodified metals and alloys" \\ 18 Injenernaya Str., Novosibirsk, 630090, Russia
}

Received 28.04.2016, received in revised form 24.11.2016, accepted 18.02.2017

The article considers influence of nanoparticle additions on structure and mechanical properties of aluminium alloys Al99.7 and AlSi12. Powders for casting strengthening have been selected according to results of the intramold modification. The samples with refined grain size, improved hardness and strength have been obtained.

Keywords: casting, composite materials, nanoparticles, nanopowders, modification, macrostructure, microstructure, hardness, strengthening.

Citation: Sukhodaev P.O., Redkin V.E., Bogdanova T.A., Kuznetsov V.A. Influence of nanoparticles on the structure and mechanical properties of aluminium alloys, J. Sib. Fed. Univ. Eng. technol., 2017, 10(3), 317-326. DOI: 10.17516/1999-494X2017-10-3-317-326.

(c) Siberian Federal University. All rights reserved

* Corresponding author E-mail address: entro34@gmail.com 


\title{
Влияние наночастиц на структуру
}

\section{и механические свойства алюминиевых сплавов}

\author{
П.О. Суходаев ${ }^{\mathrm{a}}$, В.Е. Редькин ${ }^{\mathrm{a}}$, \\ Т.А. Богданова ${ }^{\sigma}$, В.А. Кузнецов \\ ${ }^{a}$ Сибирский федеральный университет \\ Россия, 660074, Красноярск, ул. Киренского, 28 \\ ${ }^{\sigma} \mathrm{OOO} « \mathrm{KuK»}$ \\ Россия, 660111, Красноярск, ул. Пограничников, 42 \\ ${ }^{8} \mathrm{OОО} \mathrm{«Наномодифицированные} \mathrm{металльи} \mathrm{и} \mathrm{сплавыл»}$ \\ Россия, 630090, Новосибирск, ул. Инженерная, 18
}

В статье рассмотрено влияние добавок нанопорошков на структуру и механические свойства сплавов алюминия АК12 и А7. По результатам внутриформенного модифицирования выбраны порошки для упрочнения отливок. Получены образиы с уменьшенным размером зерен, обладающие повыщенной твердостью и прочностью.

Ключевые слова: литье, композиционные материалы, наночастицы, нанопорочки, модифицирование, макроструктура, микроструктура, твердость, упрочнение.

\section{Введение}

Развитие промышленности, появление более совершенной техники постоянно требуют создания новых высококачественных материалов. В последние несколько лет вместе с популяризацией нанотехнологий особенно усилился интерес к нанокомпозитам на металлической основе. Было предложено несколько способов получения сплавов, содержащих наночастицы $(\mathrm{HЧ)} \mathrm{в} \mathrm{качестве} \mathrm{упрочняющей} \mathrm{фазы.} \mathrm{Основное} \mathrm{преимущество} \mathrm{добавок} \mathrm{НЧ} \mathrm{(ex-situ)} \mathrm{перед} \mathrm{дру-}$ гими методами повышения прочности металлов, в частности выделения упрочняющей фазы из пересыщенных растворов, - это возможность контролируемого введения в матрицу новой фазы с нужной дисперсностью и морфологией. Теория и эксперимент показывают, что НЧ обладают преимуществом по сравнению с частицами микронного размера, позволяя более эффективно реализовать механизмы упрочнения металлов дисперсными включениями [1-4]. В качестве базового сплава для композитов широкого назначения особый интерес проявляется к алюминию как к металлу, широко применяемому в транспорте, авиастроении, космической технике и других областях, и обладающему высокой удельной прочностью.

Однако производство нанокомпозитов ограничивается сложностями, связанными с особенностями и свойствами материалов в наноразмерном состоянии. Прежде всего это затрагивает получение нанокомпозитов методами литья, где имеется специфика взаимодействия твердых частиц и жидкой матрицы на межфазной границе, проявляющаяся в образовании агрегатов под действием капиллярных и Ван-дер-Ваальсовых сил и в плохом смачивании, приводящим к отслоению НЧ от матрицы. Учитывая эти сложности, исследователи стремятся разработать различные технологии изготовления литых нанокомпозитов, в которых решается одна или несколько задач (повышенная прочность материалов, масштабность производства, экономическая эффективность, простота, технологичность и т.д. [2, 5, 6]). Тем не менее в боль- 
шинстве работ по данной тематике используется небольшой набор нанопорошков, чаще всего представленный оксидом кремния, который характеризуется наименьшим углом смачивания жидким металлом. В результате ограниченным оказывается применение других перспективных наноматериалов - нанотрубок, наноалмазов, электровзрывных керамических порошков и др., содержащих частицы значительной прочности и высокой дисперсности.

В данной работе авторами использована технология внутриформенного модифицирования, позволяющая улучшить усвоение широкого спектра НЧ жидким алюминиевым расплавом и быстро оценить их влияние на структуру отлитого металла [5]. В первой части экспериментов по этой технологии изготавливали образцы литьем в песчаную форму с использованием восьми видов порошков. Во второй части с использованием отобранных порошков отливали образцы в кокиль для испытаний на твердость.

\section{1. Экспериментальная часть}

\section{1. Внутриформенное модифицирование при литье в песчаную форму}

Технология внутриформенного модифицирования позволяет вносить частицы в расплав непосредственно при заливке. Схема литейной 6-позиционной формы приведена на рис. 1.

Металл при такой схеме заполняет форму, насыщаясь модификатором, что обеспечивает возможность быстрого заполнения из одного ковша нескольких форм. Фильтры предотвращают расплав от загрязнения.

Модификатор в виде таблетки изготавливали путем перемешивания медного порошка марки ПМС-1 с используемыми нанопорошками в шаровой мельнице в течение 5 мин в соотношении 5 к 1 по массе. Массу таблетки выбирали так, чтобы содержание порошков в матрице составляло 0,1 масс. \%, при котором возможно достижение упрочнения без потери пластичности [7].

С помощью данного способа было получено 10 групп образцов, содержащих различные нанопорошки; состав модификаторов приведен ниже:

1) Медь, ПМС-1 (без углеродных добавок); 2) медь + технический углерод (ГОСТ 7885-86); 3) медь + технический углерод термообработанный; 4) медь + многослойные углеродные на-

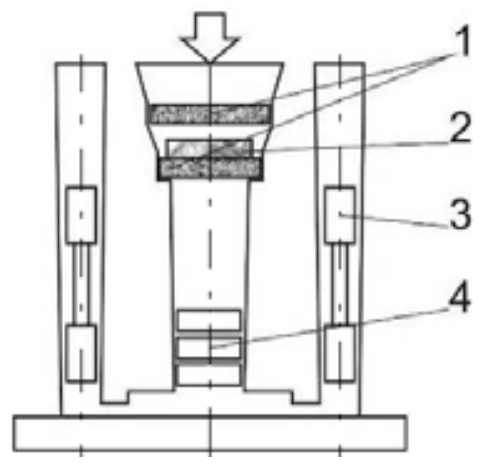

Рис. 1. Пресс-форма для изготовления литейных форм: 1 - керамические фильтры; 2 - модификатор в алюминиевой фольге; 3 - образец на растяжение; 4 - образец для микроструктурных и дюраметрических исследований и для проведения химического анализа 
нотрубки (УНТ) производства института катализа г. Новосибирск; 5) медь + однослойные УНТ производства компании «OcSiAl»; 6) медь + ультрадисперсный алмазографитовый порошок детонационного синтеза, полученный по красноярской технологии (УДП-АГ - ТУ 40-206791001-91); 7) медь + ультрадисперсный алмазный порошок (УДП-А - по ТУ 3974-001-10172699-94); 8) медь + карбид бора наноразмерный (СибГИУ г. Новокузнецк); 9) медь + механоактивированный графит (ИЦМИМ СФУ); 10) контрольный образец без модификатора.

Медь была выбрана как пластичный и непирофорный материал, способный эффективно образовывать покрытия на керамике при помоле в шаровой мельнице, что улучшает смачивание порошков. В качестве матричного металла был использован сплав алюминия с кремнием марки АК12. Температура сплава при разливке составляла $720{ }^{\circ} \mathrm{C}$. После заливки и охлаждения заготовок из них вырезали образцы для исследования структуры и механических свойств [8].

Во всех образцах, содержащих НЧ, наблюдалось уменьшение размера зерна (определенное по ГОСТ 21073.0-75), величина которого и коэффициент модифицирования $K$ представлены на рис. 2 и 3.

$$
K=D / d \text {, }
$$

где $D$ - величина зерна образца без модификатора (№10), мкм; $d$ - величина зерна модифицированного образца, мкм.

Видим, что наибольшего измельчения удалось достичь при использовании углеродных наноматериалов и карбида бора. Это можно объяснить тем, что данные материалы обладают наибольшей дисперсностью и при попадании в расплав создают большое количество центров кристаллизации.

При исследовании макроструктуры у некоторых образцов было выявлено наличие дефектов газоусадочного характера и неравномерность структуры в осевом направлении. Это связа-

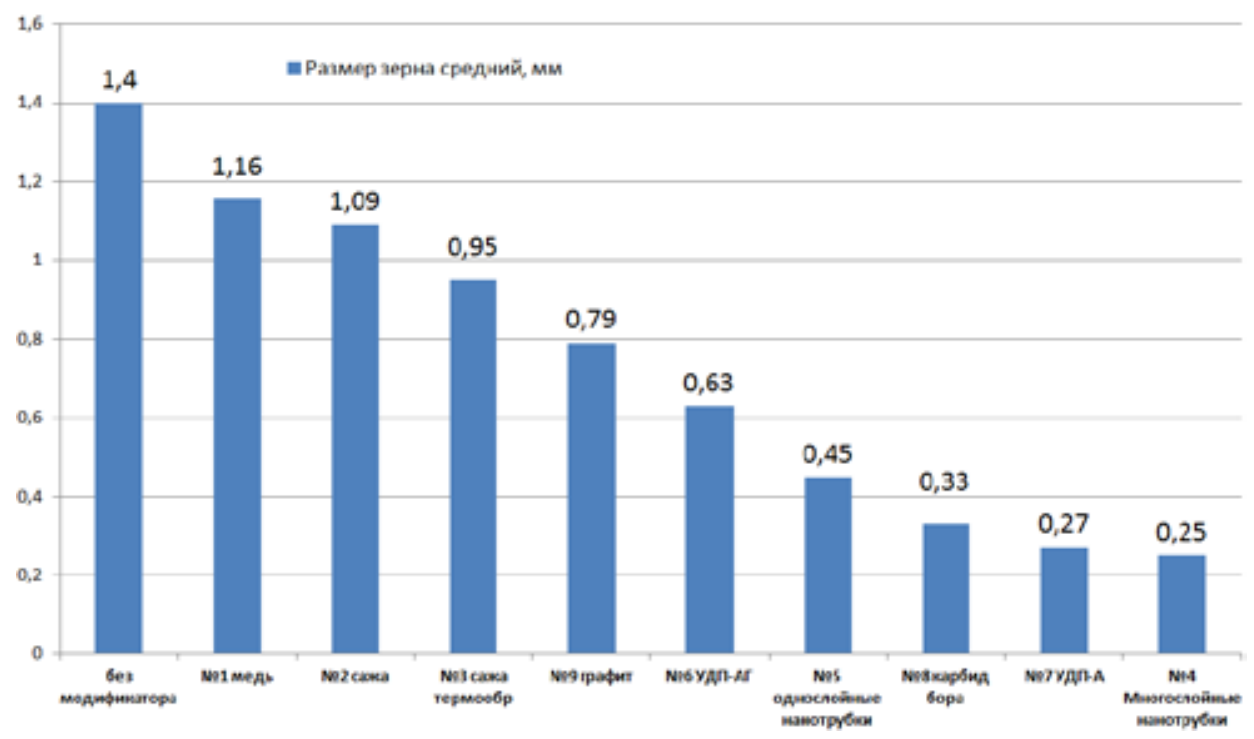

Рис. 2. Величина зерна в структуре образцов 


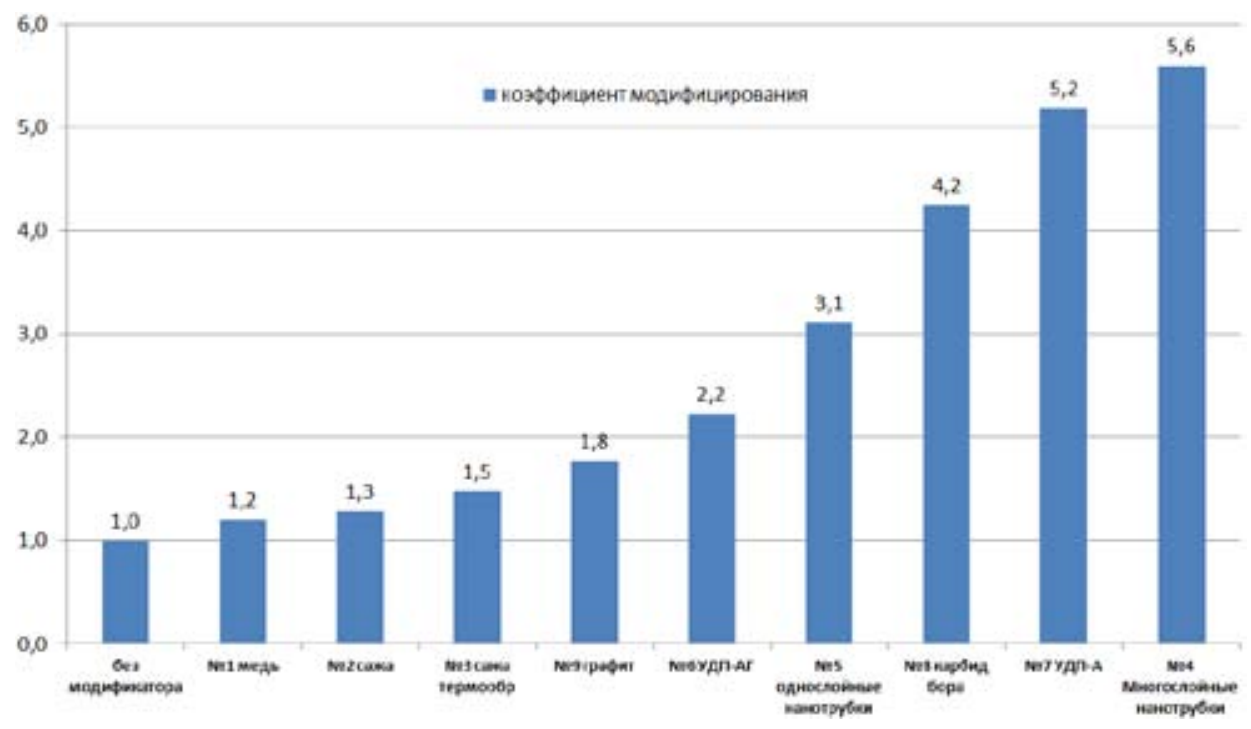

Рис. 3. Коэффициент К
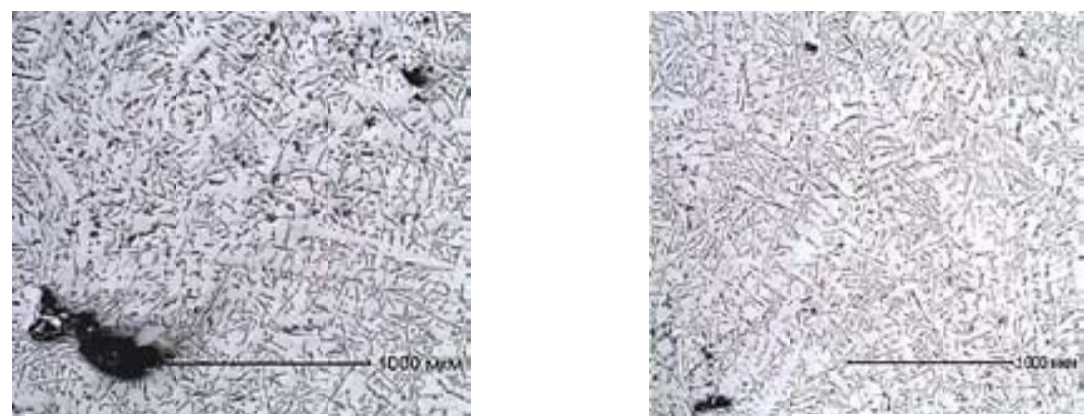

Рис. 4. Микроструктура базового (слева) и модифицированного наноалмазами (справа) сплава АК12

но с отсутствием перемешивания, усадкой при литье в песчаную форму, наличием адсорбированных газов на поверхности НЧ, которые не успевают выйти до затвердевания.

Микроструктура всех образцов представляет структуру силумина эвтектического состава, которая состоит из доли $\alpha$-твердого раствора алюминия и немодифицированной эвтектики (рис. 4).

Вырезка образцов для испытаний механических свойств после разрыва проводилась из «донной» части исследуемых образцов по 4 штуки от каждого. Результаты испытаний представлены на рис. 5. Исследование изломов разрывных образцов показало присутствие в структуре дефектов в виде пор, разрушения имеют идентичный хрупкий характер (рис. 6). Уровень относительного удлинения всех представленных образцов не превышает 2 \%.

Из-за повышенного содержания адсорбированных газов в порошках с наивысшей удельной поверхностью - нанотрубках, карбиде бора и наноалмазах прочность образцов с этими модификаторами оказалась самой низкой из всех, несмотря на минимальный размер зерен, зафиксированный в этих образцах. 


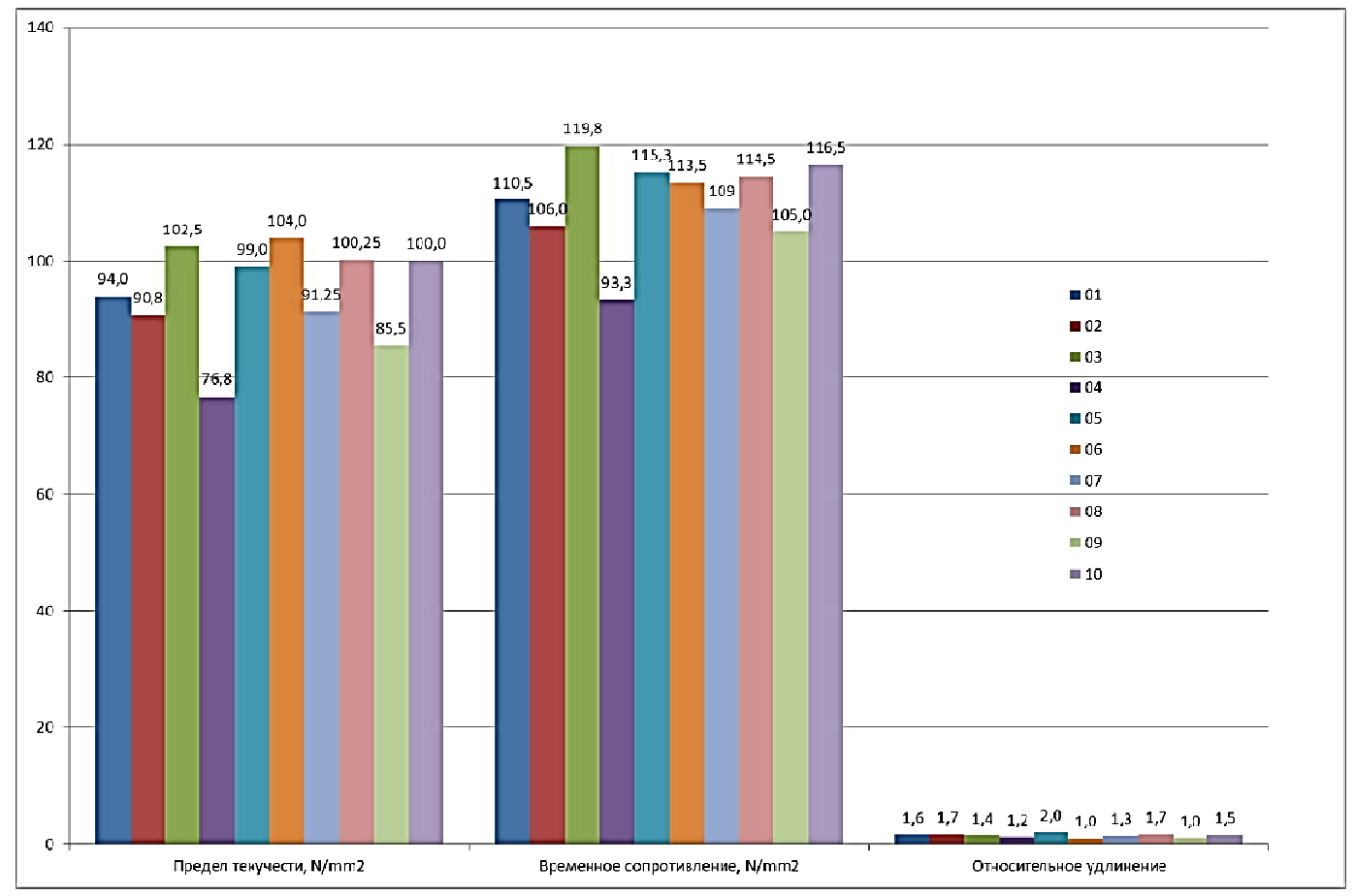

Рис. 5. Уровень механических свойств образцов

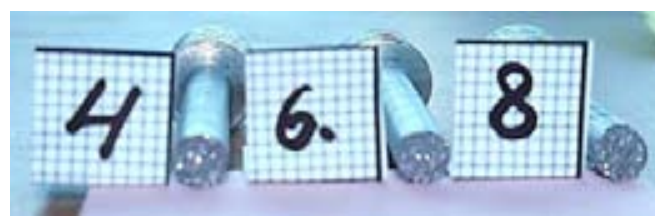

Рис. 6. Изломы образцов после испытаний на разрыв

\section{2. Литье в кокиль}

Во второй части экспериментов проводилось литье в кокиль. Из используемых порошков были отобраны УДП-А и УДП-АГ, при применении которых были получены хорошие результаты уменьшения зерна. Кроме того, эти материалы обладают относительно низкой стоимостью и могут производиться в больших масштабах по сравнению с нанотрубками. Также использовался оксид алюминия электровзрывного синтеза (производства Института сильноточной электроники, г. Томск).

Изучение гранулометрического состава наноалмаза и оксида алюминия проводилось путем осаждения в дисковой центрифуге CPS 24000. Метод основан на седиментации частиц в жидкости и отличается от других методов высоким разрешением, точностью и широким диапазоном измерения. Главный элемент центрифуги - диск, в котором происходит осаждение суспензии исследуемого вещества от центра до края в центробежном поле сил, создаваемым вращением со скоростью до 24000 об/мин. На рис. 7 представлено распределение порошка УДП-А по размерам. 
На распределении виден пик 12 нм и небольшой пик ближе к началу координат, который плохо различим на данном рисунке. Если ограничить ось абсцисс областью в начале координат и растянуть, то вид распределения преобразуется в изображенный на рис. 8 .

Здесь малый пик 4 нм хорошо различим. Он, вероятно, являет собой первичные неагрегированные частицы [9].

На рис. 9 представлено распределение порошка оксида алюминия.

Наибольшее количество частиц здесь имеет двойной пик - 15 и 20 нм.

Для литья использовался первичный алюминий марки А7, который нагревали в титановом тигле до температуры $790{ }^{\circ} \mathrm{C}$, после чего в расплав помещали таблетку-модификатор, изготов-

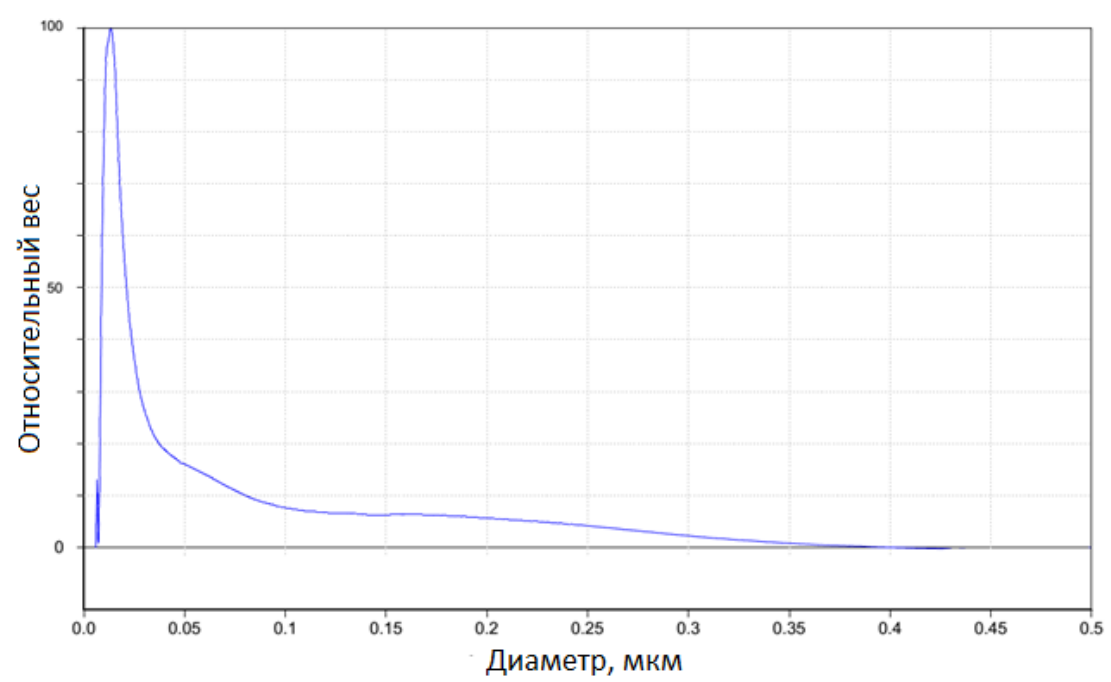

Рис. 7. Гранулометрический состав порошка УдП-А

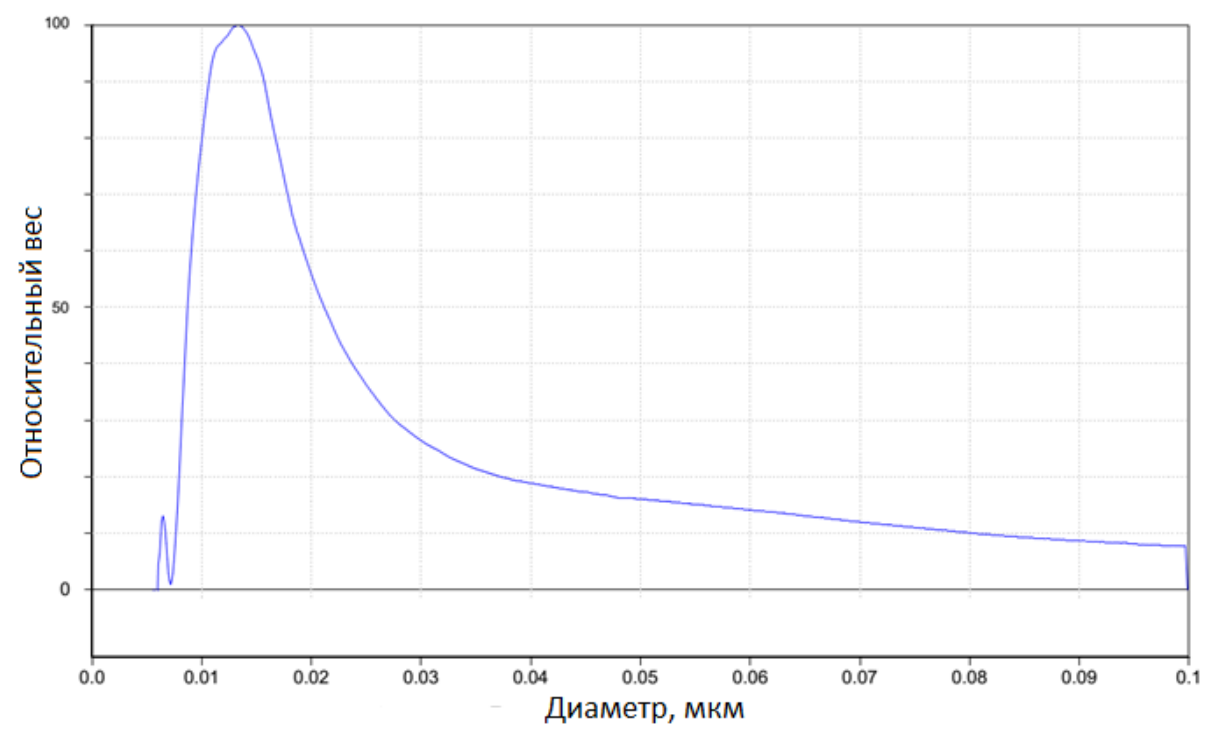

Рис. 8. Гранулометрический состав порошка УДП-А (часть графика до 0,1 мкм) 


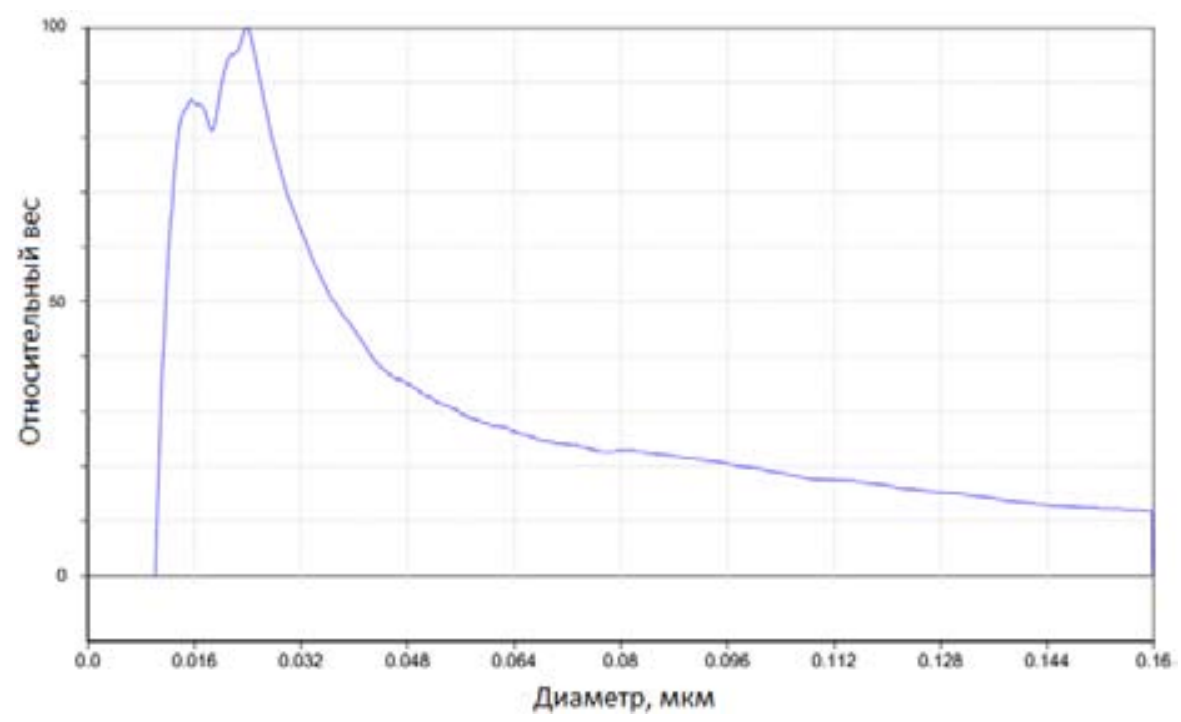

Рис. 9. Гранулометрический состав порошка $\mathrm{Al}_{2} \mathrm{O}_{3}$ электровзрывного синтеза

ленную так же, как и при первом эксперименте. Расплав выдерживали 15 мин и затем разливали в кокиль. Во время выдержки модификатор растворялся, и газам было достаточно времени для выхода из расплава. Образцы отливались с двумя массовыми содержаниями каждого порошка $-0,05$ и $0,1 \%$.

Макроструктура и размер зерен отлитых образцов приведен на рис. 10 и 11.

В образце, содержащем $\mathrm{HЧ}_{2} \mathrm{Ol}_{3}$, удалось достичь 10-кратного уменьшения зерен.

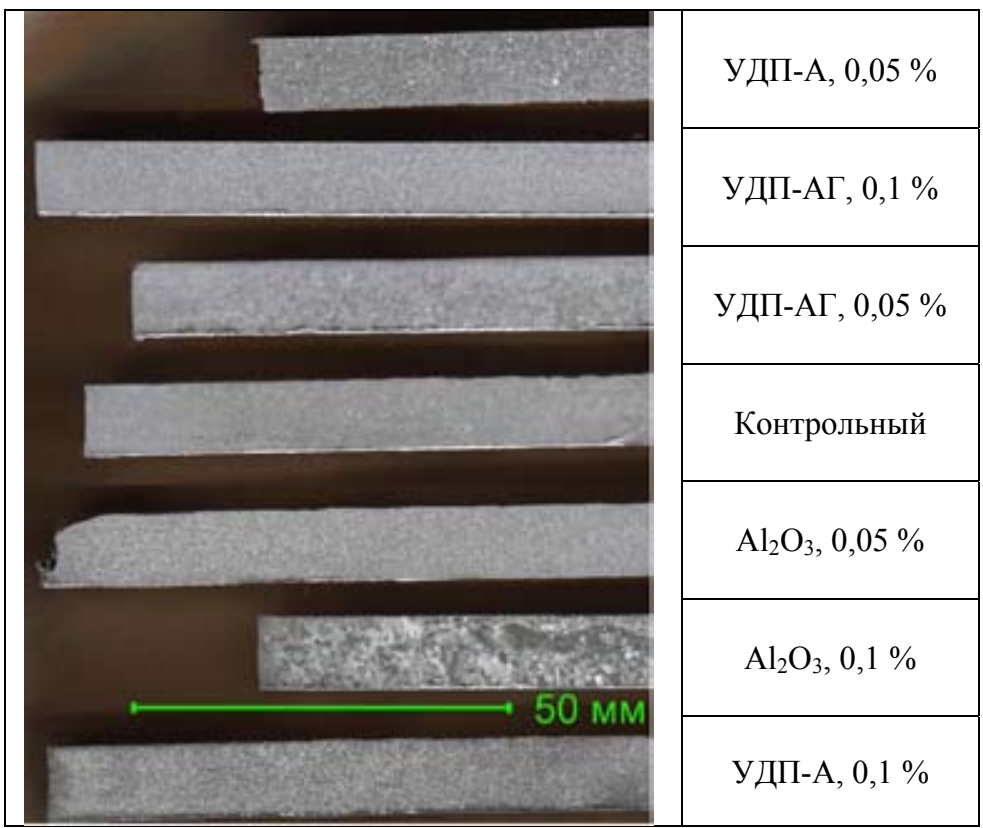

Рис. 10. Макроструктура отлитых в кокиль образцов 


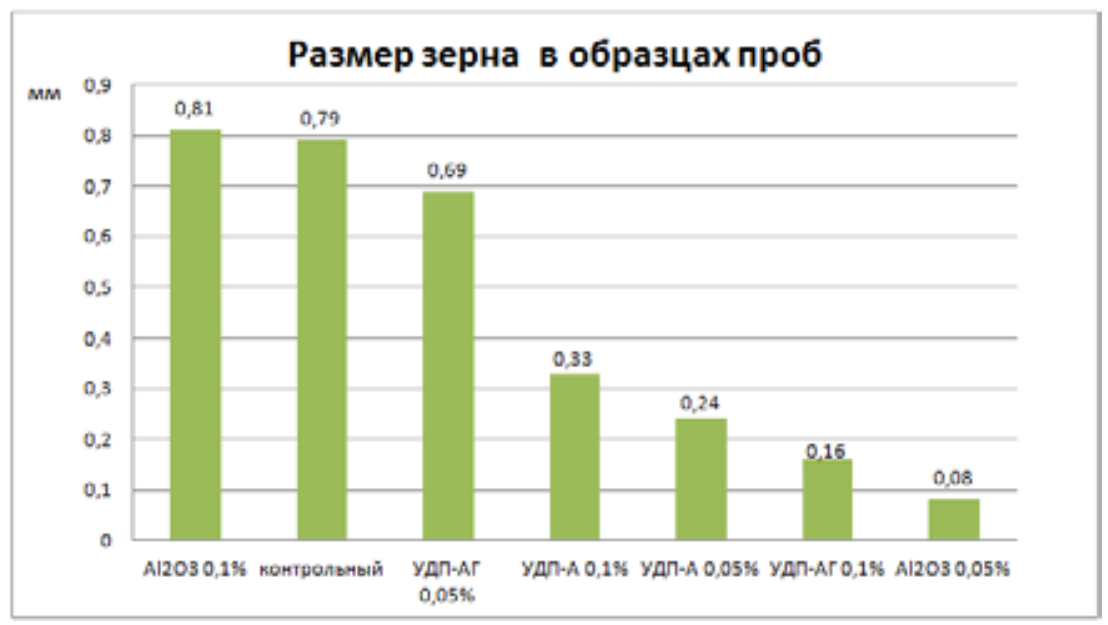

Рис. 11. Размер зерна образцов

Таблица. Твердость образцов, отлитых в кокиль

\begin{tabular}{|l|c|c|c|c|c|c|c|}
\hline \multicolumn{1}{|c|}{ Модификатор } & $\begin{array}{c}\text { Контрольный } \\
\text { образец }\end{array}$ & $\begin{array}{c}\text { УДП-А, } \\
0,05 \%\end{array}$ & $\begin{array}{c}\text { УДП-А, } \\
0,1 \%\end{array}$ & $\begin{array}{c}\text { УДП-АГ, } \\
0,05 \%\end{array}$ & $\begin{array}{c}\text { УДП-АГ, } \\
0,1 \%\end{array}$ & $\begin{array}{c}\mathrm{Al}_{2} \mathrm{O}_{3}, \\
0,05 \%\end{array}$ & $\begin{array}{c}\mathrm{Al}_{2} \mathrm{O}_{3}, \\
0,1 \%\end{array}$ \\
\hline Твердость, НВ & 24,1 & 27,9 & 28,5 & 25,0 & 30,1 & 24,2 & 30,1 \\
\hline $\begin{array}{l}\text { Предел прочности } \sigma_{\text {в }} \\
\text { МПа (расчет) }\end{array}$ & 87,2 & 101,0 & 103,2 & 90,5 & 109,0 & 87,6 & 109,0 \\
\hline
\end{tabular}

Твёрдость образцов, измеренная по методу Бринелля, приведена в таблице. В третьей колонке даны значения временного сопротивления, рассчитанные по соотношению [10]

$$
\sigma_{\mathrm{B}}=3,62 H B(M P a) \text {. }
$$

Можно видеть, что все модифицированные образцы обладают повышенной твёрдостью. Таким образом, используемые наноматериалы являются эффективными добавками для увеличения твердости (следовательно, и износостойкости) и механической прочности алюминия.

\section{Заключение}

Исследовано модифициравание алюминиевых сплавов с помощью метода внутриформенного введения нанопорошков. Наиболее перспективные модификаторы были выбраны для получения упрочненных образцов.

При литье в кокиль с помощью добавок нанопорошков удалось достичь уменьшения размера зерна в полученных сплавах до 10 раз. Значения твердости, полученные в модифицированных образцах, на 20-25 \% выше, чем у базового сплава.

Дальнейшие исследования могут быть направлены в сторону подбора оптимального гранулометрического состава нанопорошков, что может улучшить их инокулирующую способность [11] и в большей степени измельчить структуру.

$$
-325-
$$




\section{Список литературы}

[1] Goetzel C.G. Dispersion strengthened alloys: "The possibilities of light metals." Journal of metals, 1959, 11(3), 189-194.

[2] Крушенко Г.Г., Балашов Б.А., Василенко 3.А., Фильков М.Н., Миллер Т.Н. Повышение механических свойств алюминиевых литейных сплавов с помощью ультрадисперсных порошков. Литейное производство, 1991, 4, 17-18 [Krushenko G.G., Balashov B.A., Vasilenko Z.A., Fil'kov M.N., Miller T.N. Increasing the mechanical properties of aluminium cast alloys via ultradisperse powders. Liteinoye proizvodstvo, 1991, 4, 17-18 (in Russian)]

[3] Zhang Z., Chen D.L. Contribution of Orowan strengthening effect in particulate-reinforced metal matrix nanocomposites. Materials Science and Engineering: A, 2008, 483, 148-152.

[4] Mirza F.A., Chen D.L. A unified model for the prediction of yield strength in particulatereinforced metal matrix nanocomposites. Materials, 2015, 8(8), 5138-5153.

[5] Кузнецов В.А. Влияние ультрадисперсных порошков тугоплавих материалов на свойства литых изделий из черных и цветных металлов и сплавов, автореф. дис. ... канд. техн. наук. Красноярск, 2013, 26 с. [Kuznetsov V.A. The influence of refractory material ultra-disperse powders on properties of cast products from ferrous and non-ferrous metals and alloys, Thesis ... cand. of tech. Sci. Krasnoyarsk, 2013, 26 p. (in Russian)]

[6] Li X., Yang Y., Weiss D. Ultrasonic cavitation based dispersion of nanoparticles in aluminum melts for solidification processing of bulk aluminum matrix nanocomposite: Theoretical study, fabrication and characterization. AFS Transactions, 2007, 115(07-133), 249-260.

[7] Сабуров В.П., Черепанов А.Н., Жуков М.Ф., Галевский Г.В. и др. Плазмохимический синтез ультрадисперсных порошков и их применение для модифицирования металлов и сплавов (Низкотемпературная плазма. T. 12). Новосибирск: Наука, 1995. 344 с. [Saburov V.P., Cherepanov A.N., Zhukov M.F., Galevsky G.V., et. al. Plasma-chemical synthesis of ultra-disperse powders and their application for modification of metals and alloys (Low temperature plasma. Vol. 12). Novosibirsk: Nauka, 1995. 344 p. (in Russian)]

[8] Суходаев П.О., Богданова Т.А., Кузнецов В.А., Редькин В.Е. Литые композиционные материалы на основе алюминия, упрочненные наночастицами. Евразийский союз ученых, 2014, 4(4), 117-120 [Sukhodaev P.O., Bogdanova T.A., Kuznetsov V.A., Red'kin V.E. Aluminium-based cast composite materials modified with nanoparticles. Eurasian union of scientists, 2014, 4(4), 117-120 (in Russian)]

[9] Ставер А.М., Губарева Н.В., Лямкин А.И., Петров Е.А. Ультрадисперсные алмазные порошки, полученные с использованием энергии взрыва. Физика горения и взрыва, 1984, 20(5), 100-104 [Staver A.M., Gubareva N.V., Lyamkin A.I., Petrov E.A. Ultra-disperse diamond powders, obtained with explosion energy application. Combustion, explosion and shock waves, 1984, 20(5), 100-104 (in Russian)]

[10] Фридман Я. Б. Механические свойства металлов. Часть 2. Механические испытания. Конструкционная прочность. М.: Машиностроение, 1974. 368 c. [Fridman Y.B. Mechanical properties of metals. Part 2. Mechanical testing. Structural strength. Moscow: Mashinostroyeniye, 1974. 368 p. (in Russian)]

[11] Greer A.L. Grain refinement of alloys by inoculation of melts. Philosophical transactions of the Royal Society of London A: mathematical, physical and engineering sciences, 2003, 361(1804), 479-495. 